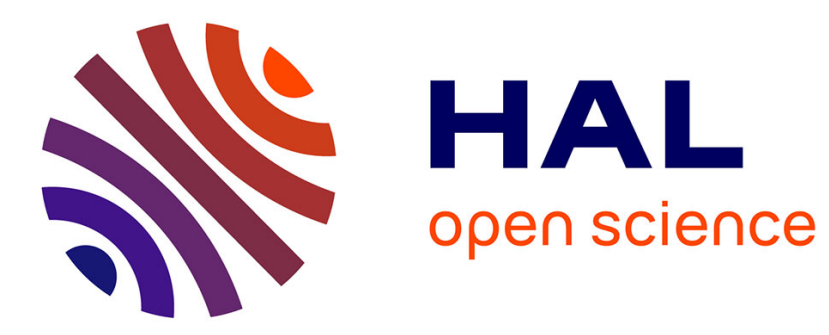

\title{
Selective reflection from sodium vapour at low densities
}

\author{
A.L.J. Burgmans, J.P. Woerdman
}

\section{To cite this version:}

A.L.J. Burgmans, J.P. Woerdman. Selective reflection from sodium vapour at low densities. Journal de Physique, 1976, 37 (6), pp.677-681. 10.1051/jphys:01976003706067700 . jpa-00208462

\section{HAL Id: jpa-00208462 https://hal.science/jpa-00208462}

Submitted on 1 Jan 1976

HAL is a multi-disciplinary open access archive for the deposit and dissemination of scientific research documents, whether they are published or not. The documents may come from teaching and research institutions in France or abroad, or from public or private research centers.
L'archive ouverte pluridisciplinaire HAL, est destinée au dépôt et à la diffusion de documents scientifiques de niveau recherche, publiés ou non, émanant des établissements d'enseignement et de recherche français ou étrangers, des laboratoires publics ou privés. 


\title{
SELECTIVE REFLECTION FROM SODIUM VAPOUR AT LOW DENSITIES
}

\author{
A. L. J. BURGMANS and J. P. WOERDMAN \\ Philips' Research Laboratories, Eindhoven, The Netherlands
}

(Reçu le 21 janvier 1976, accepté le 19 février 1976)

\begin{abstract}
Résumé. - On a étudié en détail la réflexion d'un faisceau lumineux émis par un laser à colorant accordable au voisinage des raies de résonance du sodium $D_{1}$ et $D_{2}$, à la surface de séparation verrevapeur de sodium (de faible densité : $10^{14}-10^{16}$ atomes $\mathrm{cm}^{-3}$ ). Les spectres observés sont plus fins que ceux que prévoit la théorie habituelle de la dispersion. Les résultats expérimentaux sont comparés à ceux que prédisent des calculs récents fondés sur une théorie nouvelle. Cette dernière tient compte, comme l'ancienne, des collisions entre les atomes, mais aussi des collisions des atomes sur les parois de verre de la cellule.

Abstract. - We report an extensive study of the reflectivity of a glass-sodium vapour interface near the sodium $D_{1}$ and $D_{2}$ resonance lines for low sodium vapour densities $\left(10^{14}-10^{16}\right.$ atoms $\left.\mathrm{cm}^{-3}\right)$. The observed reflection spectra are narrower than predicted by conventional dispersion theory. The experimental results are compared with recent calculations based on a theory in which not only atom-atom collisions are taken into account, as in the conventional theory, but also atom-wall collisions.
\end{abstract}

1. Introduction. - The reflectivity of a glass-vapour interface shows resonant behaviour near a resonance line of the vapour. This phenomenon is known as selective reflection and was first-observed by Wood [1] in 1909. Selective reflection is usually described in terms of a complex refractive index as given by conventional dispersion theory for atomic vapours [2]. The experiments on selective reflection, e.g. those performed by Lauriston and Welsh [3] on sodium vapour between 10 torr and 300 torr can be understood in terms of this theory.

In 1954, however, Cojan [4] did selective reflection experiments on mercury vapour that raised some doubts as to the validity of the conventional dispersion theory at low vapour densities. According to the conventional theory, the width of the selective reflection spectra is never smaller than the Doppler width [5] $\Delta v_{\mathrm{D}}$. At low vapour densities, such that the sum of the natural line width $\Delta v_{\mathrm{N}}$ and the collisional line width $\Delta v_{\mathrm{C}}$ is smaller than $\Delta v_{\mathrm{D}}$, Cojan's spectra were narrower than the Doppler width, i.e. narrower than predicted by the conventional dispersion theory. The evidence, however, was marginal due to the limited experimental possibilities at the time. In order to account for his observations Cojan set up a dispersion theory including not only atom-atom collisions, as in the conventional dispersion theory, but also atom-wall collisions. His theoretical work was restricted to specular wall collisions, i.e. collisions in which the induced polarization of the colliding atom is conserved. Although wall collisions are most probably of the diffuse type, meaning that the induced polarization of an atom is lost upon a collision, Cojan's modified dispersion theory serves to illustrate the possibility of spectral narrowing at low densities.

Recently [6], it was clearly demonstrated on sodium that spectral narrowing occurs in selective reflection when $\left(\Delta v_{N}+\Delta v_{C}\right) / \Delta v_{D}<1$. Sodium was chosen since its $3{ }^{2} \mathrm{~S}_{1 / 2}$ ground state has a hyperfine doublet splitting of $1772 \mathrm{MHz}$ (see Fig. 1), which is approximately equal to the Doppler width and therefore provides a sensitive indicator of spectral narrowing.

Schuurmans [7] has modified the conventional dispersion theory by taking into account the effect of diffuse wall collisions. His results are in qualitative agreement with the experiments as reported in reference [6]. There was however a quantitative discrepancy. Further experiments on sodium have therefore been performed in order to obtain accurate quantitative experimental results for the selective reflection spectra.

The results of this study on the sodium $D_{1}$ and $D_{2}$ resonance lines are reported in this paper and compared with the theory of reference [7].

2. Theory. - The reflectivity $R$ of a glass-vapour interface for normally incident light is given by the Fresnel formula :

$$
R=\left|\frac{n_{\mathrm{gl}}-M}{n_{\mathrm{gl}}+M}\right|^{2}
$$




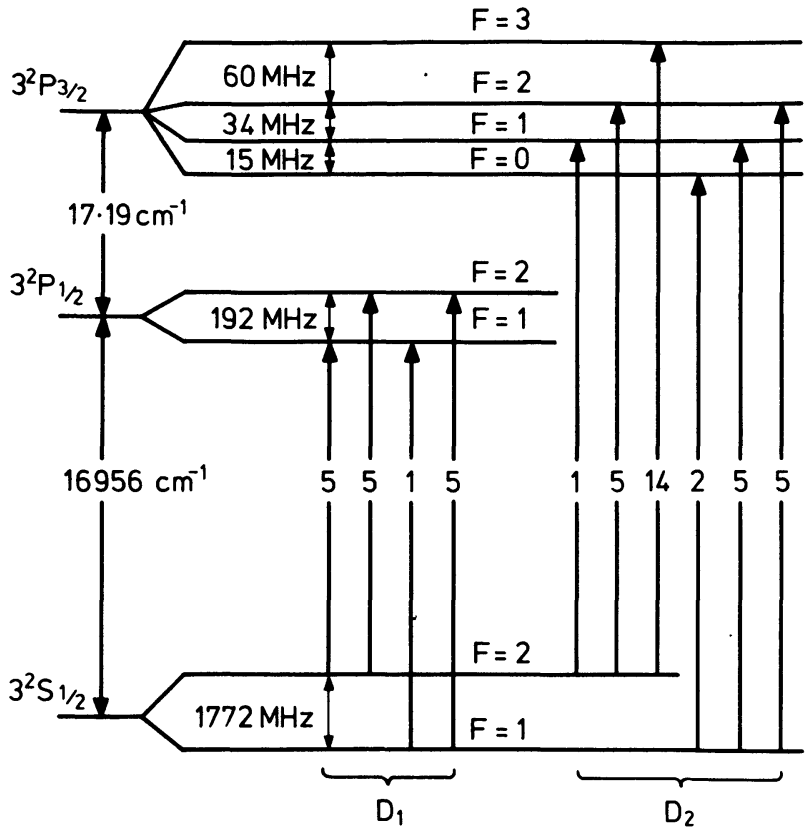

Fig. 1. - Hyperfine structure and relative line strengths of the sodium $\mathrm{D}_{1}$ and $\mathrm{D}_{2}$ resonance lines.

where $n_{\mathrm{gl}}$ is the refractive index of the glass and $M$ the surface admittance [8]. In the framework of the conventional dispersion theory Voigt has derived [9] an expression for the quantity $M$ which is to first order in the density and for a Maxwellian velocity distribution of the vapour atoms :

$$
M-1=\frac{K}{\sqrt{\pi}} \int_{-\infty}^{+\infty} \frac{\mathrm{e}^{-u^{2}}}{u-\zeta_{0}} \mathrm{~d} u,
$$

where

$$
\begin{gathered}
K=\frac{1}{2 \pi}(\ln 2)^{1 / 2} \frac{e^{2} f \rho}{m v_{0}} \frac{1}{\Delta v_{\mathrm{D}}}, \\
\zeta_{0}=(\ln 2)^{1 / 2}(i \Gamma-\Delta), \\
\Gamma=\left(\Delta v_{\mathrm{N}}+\Delta v_{\mathrm{C}}\right) / \Delta v_{\mathrm{D}}, \Delta=2\left(v_{0}-v\right) / \Delta v_{\mathrm{D}}
\end{gathered}
$$

and $u$ the reduced velocity [7] of the vapour atoms. The quantity $e$ is the electron charge, $m$ the electron mass, $\rho$ the number density of the vapour, $v$ the frequency of the incident optical field, and $f$ and $v_{0}$ the oscillator strength and the transition frequency of the particular spectral line involved. Eq. (2) is easily obtained from eq. (2.8) and (2.21) of reference [7]. From eq. (2), one infers that for $\Gamma \ll 1$, the width of a selective reflection spectrum as given by the conventional dispersion theory is approximately equal to the Doppler width.

In the modified theory for diffuse wall collisions and a Maxwellian velocity distribution [7] the surface admittance $M$ is given, to first order in the density, by :

$$
M-1=\frac{2 K}{\sqrt{\pi}} \int_{-\infty}^{0} \frac{\mathrm{e}^{-u^{2}}}{u-\zeta_{0}} \mathrm{~d} u .
$$

This expression follows from eq. (3.19) and (3.20) of reference [7]. In the modified theory, the spectral width of a selective reflection spectrum is smaller than the Doppler width in case $\Gamma<1$. For $\Gamma \gg 1$, and also in the far wings of the resonance line $(|\Delta| \gg 1)$, the results of the conventional theory and the modified theory are asymptotically equal.

Let us now consider the reflectivity near the sodium $D_{1}$ and $D_{2}$ resonance lines. The energy scheme of the two lines is given in figure 1 . The hyperfine splitting in the $3^{2} \mathrm{P}_{1 / 2,3 / 2}$ state is small compared to the collisional width and will be neglected.

In accordance with the population density of the $F=1$ and $F=2$ hyperfine levels of the ground state, the surface admittance $M$ is given by [7] :

$M=\frac{3}{8} M\left(\Delta_{1}, K, \Gamma\right)+\frac{5}{8} M\left(\Delta_{2}, K, \Gamma\right)$

where

$\Delta_{i}=2\left[v\left(3{ }^{2} \mathrm{~S}_{1 / 2}, F=i \rightarrow 3{ }^{2} \mathrm{P}_{1 / 2,3 / 2}\right)-v\right] / \Delta v_{\mathrm{D}}$

In the conventional theory, the hyperfine splitting of the ground state will be masked in the reflection spectra, whereas the modified theory [7] predicts a clear resolution of that hyperfine structure at low vapour densities.

3. Experiment. - The experimental set-up for determining the selective reflection spectra is shown in figure 2. The light source was a CW single-mode dye laser (Spectra Physics 580) pumped by an argon ion laser. The linewidth of the dye laser light was about $15 \mathrm{MHz}$ and was tunable over a frequency domain of a few hundred GHz. The output power of the linearly polarized light was about $40 \mathrm{~mW}$ at the working frequencies. The beam splitter $\mathrm{S}$ split the light into the beams I and II. Beam I went in the direction of the reflection cell normal to the glassvapour interface and beam II served as a reference beam (see Fig. 2).

The reflection cell was made from gehlenite, which is a sodium-resistant glass [10]. The cell was cylindrical with a diameter of $22 \mathrm{~mm}$ and a length of $24 \mathrm{~mm}$. After the cell was baked out for several hours at $770 \mathrm{~K}$ and evacuated to $10^{-7}$ torr, high purity sodium was distilled into it. The optically polished window sealed

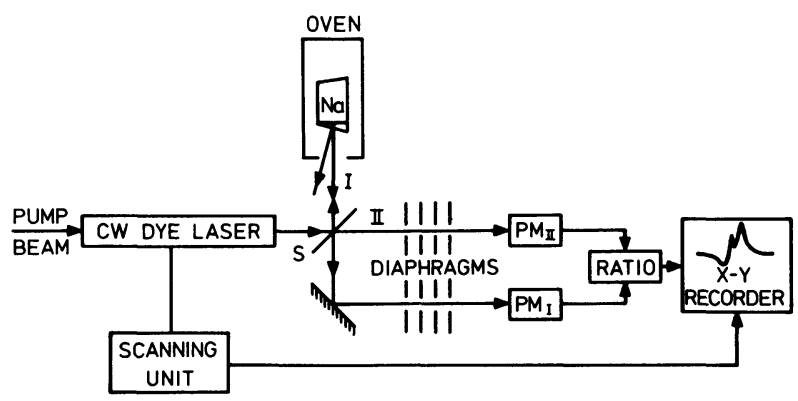

Fig. 2. - Schematic diagram of the experimental set-up. 
on to the front of the cell was wedge-shaped in order to separate the air-glass interface reflection from the reflection on the glass-vapour interface. During the experiments the cell was heated to the working temperature in an electric oven. In order to avoid condensation of sodium at the glass-vapour interface, the position of the cell in the oven was chosen such that the front window was about $30 \mathrm{~K}$ higher in temperature than the back window. The spatial temperature distribution along the cell was measured by four thermocouples and the local temperature of the vapour was known within $5 \mathrm{~K}$. The vapour density is determined by the temperature of the coldest spot in the cell and known vapour density data [11] (see Fig. 3).

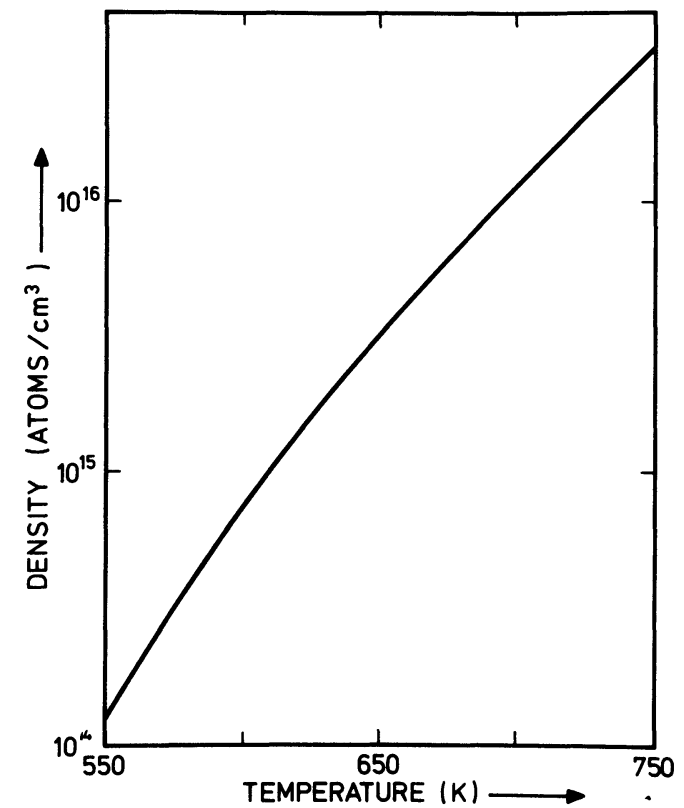

Fig. 3. - Vapour density of sodium as a function of the sodium temperature.

The intensity of the reflected light was measured with a photomultiplier and divided by the intensity of the reference beam (beam II), which was measured by a photomultiplier of the same type. In this way fluctuations in the laser output were eliminated. The ratio of the two signals was recorded on a chart recorder as a function of the frequency of the laser light.

4. Results and discussion. - The reflectivity near the sodium $\mathrm{D}_{2}$ resonance line for both the conventional dispersion theory and the modified theory [7] has been calculated ( ${ }^{1}$ ) using eq. (1), (2), (5) and (6). In the calculations use has been made of the following data :

$$
\begin{gathered}
\Delta v_{\mathrm{N}}=10 \mathrm{MHz}[12,13], \\
\Delta v_{\mathrm{C}}=0.70 \times 10^{-13} \rho \mathrm{MHz}[14,15], \\
\Delta v_{\mathrm{D}}=76.0 \mathrm{~T}^{1 / 2} \mathrm{MHz}[12], f=0.655[13]
\end{gathered}
$$

and

$$
n_{\mathrm{gl}}=1.6277 \text {. }
$$

(1) SchuUrmans, M. F. H., private communications. LE JOURNAL DE PHYSIQUE. - T. 37, № 6, JUIN 1976
In figure 4 the reflection spectrum, calculated according to the conventional dispersion theory is given for a sodium vapour temperature of $660 \mathrm{~K}$. It is seen that the hyperfine splitting of the $3{ }^{2} \mathrm{~S}_{1 / 2}$ ground state merely shows up as a small kink in the spectrum near its center.

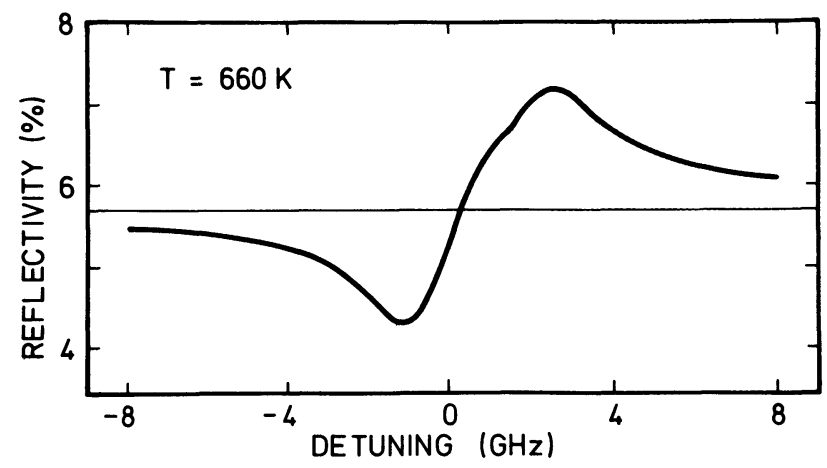

FIG. 4. - The reflectivity of a gehlenite glass-sodium vapour interface near the $D_{2}$ resonance line at $660 \mathrm{~K}$ as a function of the detuning calculated from the conventional dispersion theory. The quantity $\Delta v$ is given by $\Delta v=v-v\left(3{ }^{2} \mathrm{~S}_{1 / 2}, \mathrm{~F}=2 \rightarrow 3{ }^{2} \mathrm{P}_{3 / 2}\right)$.

The reflectivity according to the modified theory [7] is given in figure 5 for four temperatures ranging from $580 \mathrm{~K}$ to $700 \mathrm{~K}$.

A set of the experimentally determined selective reflection spectra is given in figure 6 for the same four temperatures of the condensed sodium. It is seen that for the lower temperatures the contributions of the $F=1$ and $F=2$ hyperfine levels are clearly resolved as a result of spectral narrowing. With increasing temperatures the resolution of the hyperfine splitting decreases.

Data for the reflectivity near the $D_{1}$ resonance line show a behavior similar to that near the $D_{2}$ resonance line.

From our experimental results it is clear that the conventional dispersion theory fails to describe the selective reflection spectra for low vapour densities such that $\Gamma<1$. The shape of the experimental spectra is in good agreement with the results of the modified theory, especially for temperatures above $600 \mathrm{~K}$. At $580 \mathrm{~K}$ the calculated spectrum differs from the experimental result in the sense that in the former the $F=2$ peak is about twice as high as the $F=1$ peak while in the latter the amplitudes of the two peaks are about equal. In the theoretical calculations for $580 \mathrm{~K}$, however, it is no longer justified to neglect the hyperfine splitting of the $3^{2} \mathrm{P}_{3 / 2}$ excited state. If that splitting is taken into account the height of the $F=2$ peak diminishes.

The theoretical widths of the $F=1$ and $F=2$ peaks are smaller than the experimental widths. The measured full width at half maximum of the $F=2$ peak, the maximum being taken with respect to the far wing reflectivity, is about $300 \mathrm{MHz}$ larger than the theoretical width over the whole temperature region. If the hyperfine splitting of the $3{ }^{2} \mathrm{P}_{3 / 2}$ excited state is taken 


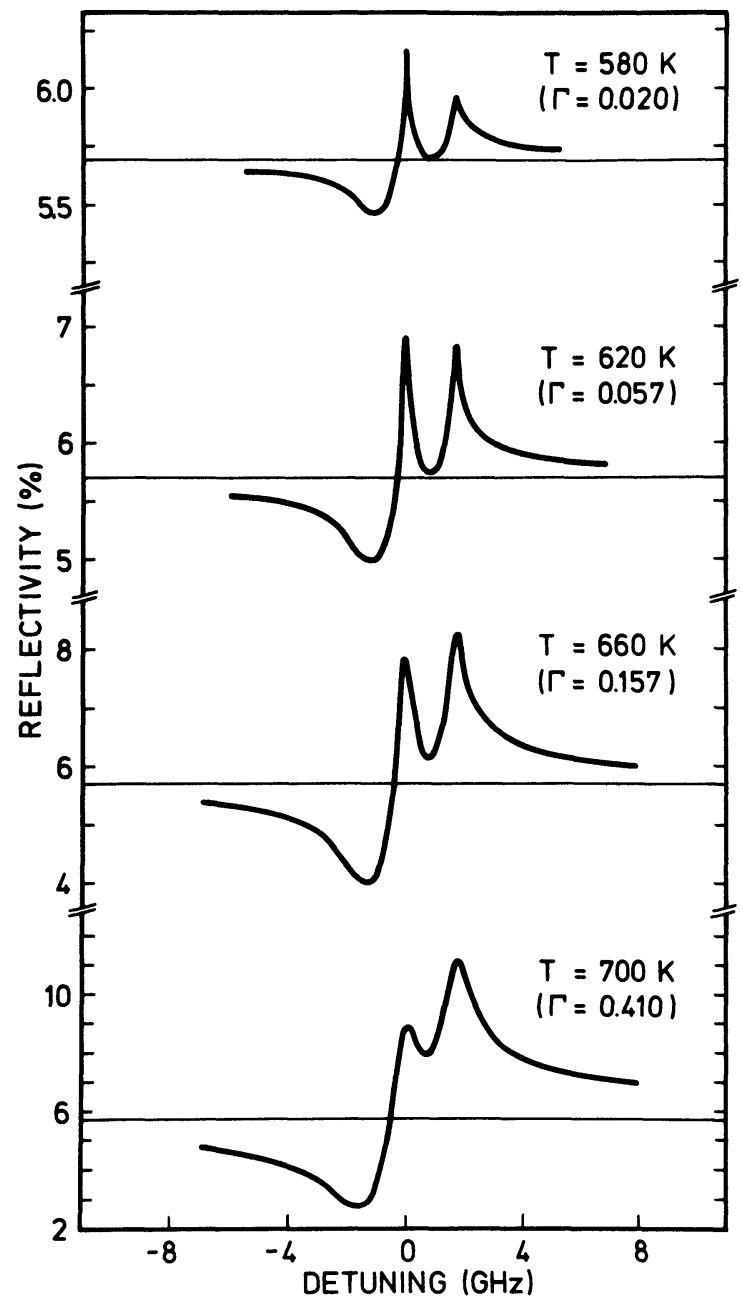

FIG. 5. - Calculated reflectivity of a gehlenite glass-sodium vapour interface near the $D_{2}$ resonance line as a function of the detuning for temperatures ranging from $580 \mathrm{~K}$ to $700 \mathrm{~K}$. The difference in the vertical scale between two successive spectra is a factor 2 .

into account in the calculations, the discrepancy in the widths will be less; but there is still a significant difference between the calculated and experimental width. The experimental width associated with the minimum in the reflectivity occurring for $\Delta v<0$ agrees with the corresponding theoretical width.

The frequency separation of the maximum of the peaks associated with $F=1$ and $F=2$ is found to be always $1.72 \mathrm{GHz}$. This is consistent with the hyperfine splitting of the $3{ }^{2} \mathrm{~S}_{1 / 2}$ ground state if one considers that the $F=2 \rightarrow F=3$ and $F=1 \rightarrow F=1,2$ are the strongest transitions (see Fig. 1). The difference between the frequencies where the spectra attain their minimum and maximum value is also about equal in experiment and theory, except at $700 \mathrm{~K}$ where the theoretical value of the frequency difference is smaller by about $1 \mathrm{GHz}$. At this temperature, however, the low density approximation becomes questionable. The exact calculation of the reflectivity suggests a larger frequency difference (cf. Fig. 1 of ref. [7]).

The amplitudes of the experimental spectra are in good agreement with theory. In the initial work reported in reference [6] amplitudes were observed that

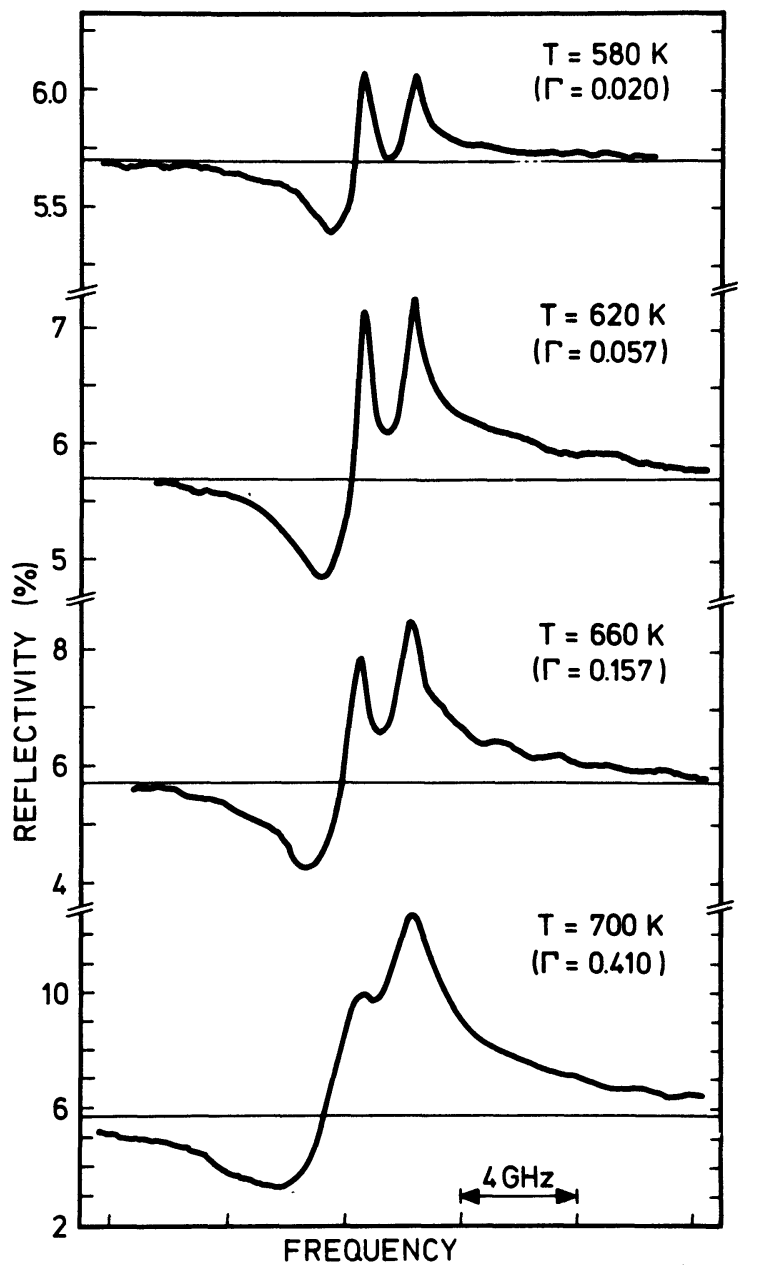

FIG. 6. - Measured reflectivity of a gehlenite glass-sodium vapour interface near the $D_{2}$ resonance line as a function of frequency for temperatures of the condensed sodium ranging from $580 \mathrm{~K}$ to $700 \mathrm{~K}$. The horizontal and vertical scales are the same as in figure 5 .

are significantly smaller than those reported in this paper. In an attempt to locate the cause of the discrepancy spectra were taken using the experimental set-up of reference [6]. Spectra measured with this light source were not different from those obtained with the Spectra Physics dye laser. Spectra were also taken using two other gehlenite cells of about the same dimensions as the one mentioned above. These experiments showed that the results are independent of the cell that is used. In spite of our efforts we were unable to explain the discrepancy mentioned above. There is, however, some evidence that it is caused by a systematic error in the temperature measurements of the earlier work. Furthermore the spectra are independent of the intensity of the incoming light for intensities ranging from $0.1 \mathrm{~mW} / \mathrm{cm}^{2}$ to $3 \mathrm{~W} / \mathrm{cm}^{2}$.

Finally we will make some remarks concerning our results. Starting experiments with a new cell, at first the sodium will react with the gehlenite. After a few times of condensing and recondensing the sodium, the glass becomes saturated. Such an accommodation of the cell has been reported by different investigators, see for example reference [16]. Therefore, it is most likely that a layer of sodium is present at the interface, 
affecting the reflected signal. The thickness of such a layer, however, can be estimated and will be at most one or two atomic diameters. This changes the amplitude of the spectra $\left({ }^{1}\right)$ by less than $10 \%$ and can therefore be ignored in view of the experimental uncertainty.

The value of the collisional width $\Delta v_{\mathrm{C}}$, used in the calculations is not accurately known in the center of a resonance line. One may wonder whether it is possible to resolve the difference in theoretical and experimental widths of the selective reflection spectra by using $\Delta v_{\mathrm{C}}$ as an adjustable parameter. This is not possible be it only for the reason that a much too large value of $\Delta v_{\mathrm{C}}$ is needed. It may be, however, that the difference in widths between the theoretical and experimental spectra is caused by the way collisional broadening is incorporated in the theory. Furthermore, the extra line broadening and line shifts near the interface, due to the presence of the glass, have not been taken into account in the theory.
In conclusion, we can say that it is clear that for low vapour densities $(\Gamma<1)$ the conventional dispersion theory fails to describe selective reflection spectra and that a more successful description can be found when atom-wall collisions are taken into account as has been done by Cojan [4] and in greater detail by Schuurmans [7]. The theoretical results of reference [7] for diffuse wall collisions and a Maxwellian velocity distribution of the vapour atoms, describe the reflection spectra in case $\Gamma<1$ very well in a qualitative sense and satisfactorily in a quantitative sense.

Acknowledgments. - We wish to express our gratitude to Dr M. F. H. Schuurmans for many helpful discussions and his continuous interest in this work. We have also gratefully benefited from his theoretical calculations on the sodium $\mathrm{D}_{2}$ resonance line. We are indebted to Dr L. Vriens for his generosity in placing the Spectra Physics dye laser at our disposal and for his hospitality during part of this research.

\section{References}

[1] Wood, R. W., Phil. Mag. 18 (1909) 187.

[2] BorN, M., Optik (Springer, Berlin) 1933.

[3] Lauriston, A. C. and Welsh, H. L., Can. J. Phys. 29 (1951) 217.

[4] Cojan, J. L., Ann. Phys. (Paris) 9 (1954) 385.

[5] The quantities $\Delta v_{\mathrm{N}}, \Delta v_{\mathrm{C}}$ and $\Delta v_{\mathrm{D}}$ are taken at full width half maximum of the absorption.

[6] Woerdman, J. P. and Schuurmans, M. F. H., Opt. Commun. 14 (1975) 248

[7] Schuurmans, M. F. H., J. Physique 37 (1976) 469.

[8] LANDAU, L. D. and LifshitZ, E. M., Electrodynamics of continuous media (Pergamon) 1963.

[9] VoIGT, W., Sitzungsber. Math. Phys. München (1912) 603.

[10] U.S. Patent No. 3563772.
[11] Hultgren, R., Desai, P. D., Hawkins, D. T., Gleiser, M., Kelley, K. K. and WaGman, D. D., Selected Values of the Thermodynamic Properties of the Elements (American Society for Metals, Metals Park, Ohio) 1973.

[12] Mitchell, A. C. G. and Zemansky, M. W., Resonance Radiation and Excited Atoms (Cambridge Univ. Press, England) 1934.

[13] Wiese, W. L., Smith, M. W. and Miles, B. M., Atom. Transitions Probabilities (MSRDS-NBS 22, Washington) 1969, Vol. II.

[14] Watanabe, K., Phys. Rev. 59 (1941) 151.

[15] Niemax, K. and PICHLeR, G., J. Phys. B 8 (1975) 179.

[16] Ioli, N., Strumia, F. and Moretti, A., J. Opt. Soc. Am. 61 (1971) 1251. 